\title{
A geografia dos resíduos sólidos urbanos (RSU) na sede do Município de Caroebe-RR
}

\author{
Euzimar do Nascimento Nunes ${ }^{1}$, Haroldo Scacabarossi ${ }^{2}$ e Maria Nélia Araújo ${ }^{3}$
}

1 Licenciada em Pedagogia e Geografia FARES / UERR, Especializada em Gestão Escolar - FACETEN

2 Doutorando em Geografia - UFC. E-mail: haroldogeo@yahoo.com.br

3 Licenciada em Pedagogia e Geografia FARES / UERR

\begin{abstract}
RESUM 0: A pesquisa teve como objetivo investigar a disposição e tratamento dos resíduos sólidos no município de Caroebe-RR ,visando melhorias para possível aplicabilidade de políticas públicas na saúde e educação dos moradores do município. A pesquisa de caráter exploratório pautou-se em levantamentos bibliográficos e de campo, buscando compreender os problemas ocasionados pela falta inadequada de local para disposição final dos Resíduos Sólidos Urbanos, colocando em riscos à saúde dos moradores. Durante a pesquisa procurou-se identificar o volume mensal e diário de resíduos gerados no município, que segundo dados coletados e pesquisas realizadas, o índice de RSU é considerado razoável.
\end{abstract}

Palavras-Chave: Resíduos Sólidos. M eio ambiente. Impacto Ambiental. Lixão. Coleta

\begin{abstract}
The research aimed to investigate the disposal and treatment of solid waste in the city of Caroebe - RR, for improvements to possible applicability of public politics in health and education of the residents of the city. The exploratory study was based on literature surveys and field, seeking to understand the problems caused by inadequate lack of place for final disposal of M unicipal Solid Waste, putting at risk the health of residents. During the research, was sought to identify the monthly and daily volume of waste generated in the city, which according to the data collected and research performed the MSW rates are considered reasonable.
\end{abstract}

Keywords: Solid Waste. Environment. Environmental impact. Landfill. Rubbish

Sumário: 1 Introdução; 2 Legislação dos Resíduos Sólidos Urbanos; 3 Aterro Sanitário; 4 Município de Caroebe; 5 Resíduos Sólidos Urbanos; 6 Metodologia; 7 Resultado e Discussões; 8 Considerações finais; Referências.

\section{INTRODUÇÃO}

A geração de Resíduos Sólidos Urbanos é um dos principais causadores de impactos ambientais, sendo prejudicial à saúde pública, bem como a contaminação do solo, das nascentes e até mesmo na proliferação de vetores e propagação de doenças que afetam os seres humanos.

Segundo (CHRISTOFOLETTI et al. 1997), impacto ambiental é considerado como qual-

Planeta Amazônia: Revista Internacional de Direito Ambiental e Políticas Públicas 
quer ação, atividade natural ou antrópica, que produz alterações bruscas em todo o meio ambiente ou apenas em alguns dos seus componentes. É também definido como sendo "mudança sensível, positiva ou negativa, nas condições de saúde e bem-estar das pessoas e na estabilidade do ecossistema, do que depende a sobrevivência humana". Essas mudanças podem resultar de ações acidentais ou planejadas, provocando alterações direta ou indiretamente.

0 autor afirma, ainda, que qualquer ação sofrida ao meio ambiente, seja de forma naturalmente ou pela ação sofrida pelo homem no decorrer dos tempos, é chamada de impacto ambiental, sendo de forma positiva ou negativa, onde o ambiente sofra determinadas alterações.

Conforme o Programa de Pesquisas em Saneamento Básico - PROSAB (2003),

Os Resíduos Sólidos Urbanos (RSU) por ser um dos principais agentes causadores de impactos ambientais, e prejudicial à saúde pública, serão tratados os conceitos do que é Resíduos sólidos, sua classificação e sua forma de gerenciamento, quanto a deposição adequada para os municípios.

Com a implantação do Plano de Políticas Públicas voltadas para o gerenciamento dos Resíduos Sólidos Urbanos, contribuirá para a diminuição de impactos sofridos ao meio ambiente em decorrente do mau condicionamento da disposição final de RSU. É a forma adequada para disposição final desde RSU, sem que seja prejudicial ao meio ambiente, contribuindo para prevenção de doenças ocasionadas pelo mau condicionamento, identificando o índice gerado no município de Caroebe, sua disposição final e sua forma de gerenciamento.

\section{LEGISLAÇÃO DOS RESÍDUOS SÓLIDOS URBANOS}

A lei 12.305 / 2010 que trata da Política Nacional de Resíduos Sólidos - PNRS, que rege os regulamentos sobre resíduos sólidos, apresenta como um dos objetivos fundamentais, a ordem de prioridade para a gestão dos resíduos, que deixa de ser voluntária e passa a ser obrigatória: não geração, redução, reutilização, reciclagem, tratamento dos resíduos sólidos e disposição final ambientalmente adequada. Trata sobre a diferença entre resíduos e rejeitos: onde os resíduos devem ser reaproveitados e reciclados, e apenas os rejeitos devem ter disposição final.

No dia cinco de junho de dois mil e treze, com a participação de quatro municípios na Conferência Municipal do M eio Ambiente, envolvendo a participação de 49 (quarenta) pessoas, foi feito um questionário, sendo que, 19 (dezenove) participantes não fizeram parte da avaliação. 0 resultado desta avaliação foi estipulado em porcentagem para facilitar a observação e conclusão da presente avaliação. Criaram-se algumas propostas para a redução de resíduos, propostas para a construção de aterros sanitários consorciados visando à diminuição dos impactos ambientais. No município de Caroebe o Plano Municipal de Manejo de Resíduos sólidos Urbanos está em elaboração, segundo informações obtidas pelo Secretário do M eio Ambiente, tendo sido realizada apenas uma Conferência M unicipal de caráter inicial. 


\section{ATERRO SANITÁRIO}

A elaboração de projeto de aterro sanitário envolve alguns cuidados essenciais que devem ser considerados pelos agentes públicos envolvidos, tais como dados populacionais, aspectos socioeconômicos predominantes, infraestrutura de saneamento básico, aspectos morfológicos, rede de drenagem, dentre outros. Essas informações darão suporte ao dimensionamento do aterro e sua capacidade de carga, além de evitar que torne um grande complicador ambiental. No município ainda estão trabalhando no projeto para a criação do aterro sanitário, para disposição final de forma adequada, sem causar consequências futuras.

A lei 12.305/2010, art. 3o, trata da disposição final ambientalmente adequada: distribuição ordenada de rejeitos em aterros, observando normas operacionais específicas, de modo a evitar danos ou riscos à saúde pública e à segurança e, também, a minimizar os impactos ambientais adversos. Gomes (1989) aponta que a geração de resíduos está diretamente relacionada ao número de habitantes e ao tipo de população, ou melhor, aos hábitos de vida da comunidade. Para os estudos preliminares é importante, ainda, um diagnóstico do gerenciamento de resíduos sólidos que está em andamento no município.

Precisa haver um estudo sobre a variação de resíduos, a coleta e o transporte, onde precisa ter um transporte adequado, o tratamento com estes tipos de resíduos, e por último, o destino final. Segundo Zveibil (1991), quanto aos agentes químicos, à poluição atmosférica pode ser causada pela queima de lixo a céu aberto e a contaminação de lençóis d'água por substâncias químicas presentes na massa de resíduos. 0 mau acondicionamento do lixo pode causar problemas com aspectos estéticos ao bem-estar (poluição visual), sendo a exposição indevida do lixo, geradora de incômodos a população, tanto pelo odor quanto pela poluição visual.

Depósito de resíduos a céu aberto pode causar consequências à sociedade, como: mau cheiro, poluição visual, contaminação de lençol freático, e contaminação de doenças. (ZVEIBIL, 1991). 0 depósito de resíduos sólidos a céu aberto ou lixão é uma forma de deposição desordenada sem compactação ou cobertura dos resíduos, o que propicia a poluição do solo, ar e água, bem como, a proliferação de vetores de doenças. Por sua vez, o aterro controlado é outra forma de deposição de resíduo, tendo como único cuidado a cobertura dos resíduos com uma camada de solo ao final da jornada diária de trabalho, com o objetivo de reduzir a proliferação de vetores de doenças. (PROSAB, 2003).

Compreende-se necessário um trabalho de sensibilização sobre a geração de resíduos e reutilização destes materiais, onde a sociedade, conhecendo os riscos prejudiciais à saúde, pode contribuir na diminuição de resíduos.

\section{MUNICÍPIO DE CAROEBE}

O Município de Caroebe surgiu por meio do desmembramento de terras do município de São João da Baliza com a Lei Estadual n 82, de 4 de novembro de 1994. Está localizado no sudeste do Estado de Roraima na mesorregião Sul, microrregião Norte, situado nas coorde- 
nadas geográficas 5943'10" de longitude oeste e, 0053'42"de latitude Norte. Com altitude de 52 (cinquenta e dois) metros em relação ao nível do mar (SEPLAN, 2009).

Ainda em relação à localização, limita-se ao norte com o município de Caracaraí e a República Cooperativista da Guiana; ao sul com o Estado do Amazonas; a leste com o Estado do Pará e a oeste com os municípios de São João da Baliza e Caracaraí. Sua distância da área territorial de 12.065,54 km (IBGE, 2014), conforme figura 1 (um).

É composto por florestas densas, onde vivem algumas populações indígenas, como as etnias Wai-Wai, na terra indígena Trombeta/Mapuera. Suas Terras Indígenas, área Total: 6.376,32 km2 - Participação em relação ao total de terras do M unicípio: 52,70\% (SEPLAN, 2009).

Figura 1 - Mapa de localização do município

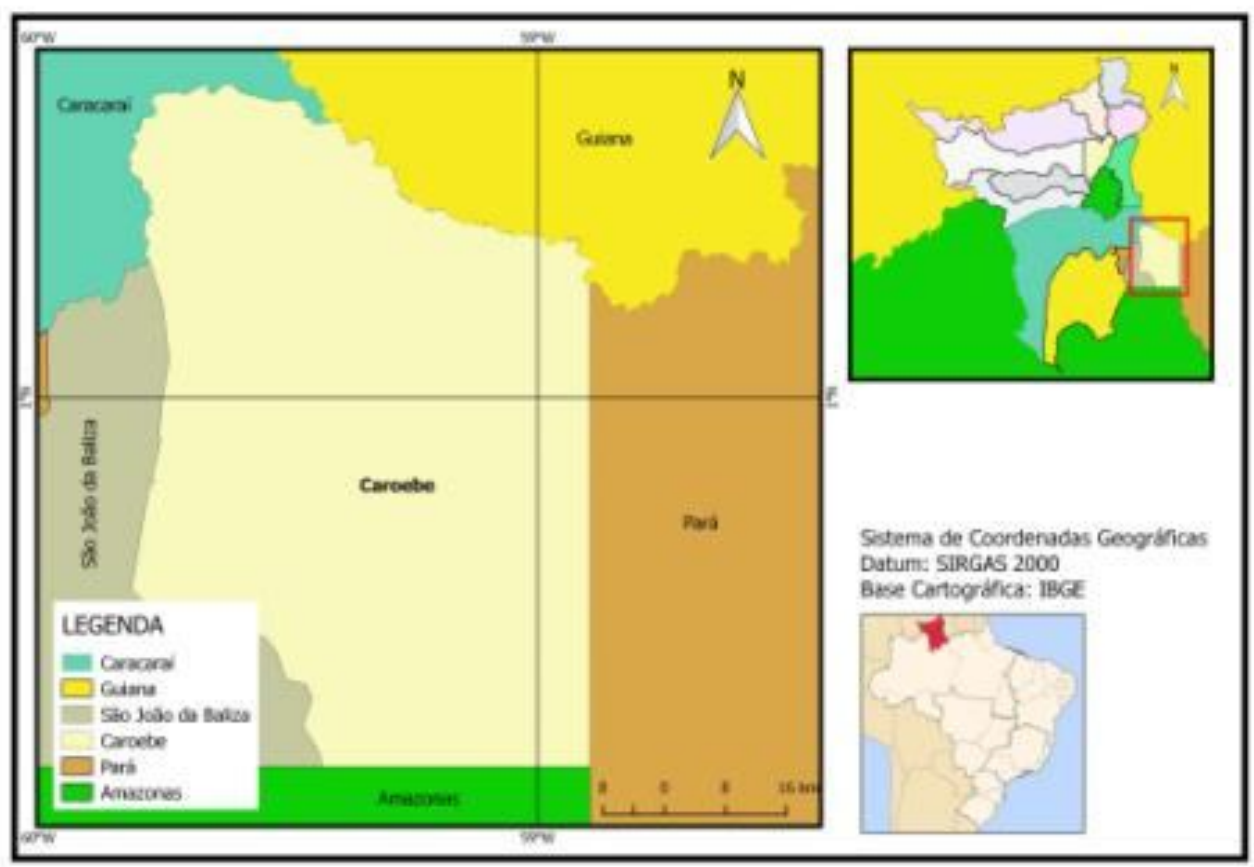

Fonte: Instituto Brasileiro de Geografia e Estatística - IBGE (2014), adaptado por SANTOS e RUFINO.

0 relevo é composto por superfície plana (70\%), áreas alagáveis ou inundáveis (terraços fluviais) e relevo fortemente ondulado (20\%). A rede hidrográfica é representada pelos rios: Novo, Caroebe e Jauaperi. Sua cobertura vegetal é do tipo floresta ombrófila densa, e suas principais vilas são Entre Rios e Jatapú. (Plano de Desenvolvimento Local Integrado e Sustentável do Município de Caroebe - PDLISM C, 2001/2004).

O clima do município é de tipo tropical chuvoso e sem estação seca, com precipitação pluviométrica relativamente elevada permitindo o desenvolvimento da zona de mata florestal; a precipitação pluviométrica é entre $1.500 \mathrm{~mm}$ e $1.750 \mathrm{~mm}$; a média da temperatura anual é de $28^{\circ} \mathrm{C}$, o intervalo de variação de temperatura no ano situa-se entre 260 e $38^{\circ} \mathrm{C}$, sua população atual é de 8.997 habitantes, segundo os dados do (IBGE, 2014). 


\section{RESÍDUOS SÓLIDOS URBANOS}

Os Resíduos Sólidos Urbanos são vistos como tudo que geramos e, logo em seguida, desprezamos no nosso cotidiano sem que haja alguma utilidade em nossas casas, bairros, ruas, etc. Os Resíduos Sólidos são, muitas das vezes, chamados de lixo e considerados pelos geradores como algo inútil, indesejável ou descartável; compõem os restos das atividades humanas. (M ANO, PACHECCO, BONELLI, 2010).

Segundo a norma brasileira (NBR 10004, 1987) - Resíduos sólidos/ classificação, resíduos sólidos são: aqueles resíduos nos estados sólidos e semissólidos, que resultam de atividades da comunidade de origem industrial, doméstica, hospitalar, comercial, agrícola, de serviços e de varrição.

De acordo com Carvalho (2010), Resíduos Sólidos Urbanos são produzidos em residências, os provenientes do comércio (bares, lojas, escritórios, hotéis, restaurantes, supermercados e outros) e aqueles que resultam da limpeza de ruas, parques, jardins, e bueiros, praias, terrenos, feiras livres, de podas de jardins e árvores. Os Resíduos Sólidos da Área Rural são provenientes de atividades agrícolas, como: embalagens de adubos, defensivos agrícolas, ração e restos de colheitas (M ANO, PACHECCO e BONELLI, 2010). Ainda, de acordo com Mano, Pachecco, Bonelli (2010), os Resíduos Sólidos se classificam em:

Quadro 1 - Classificação dos Resíduos Sólidos.

\begin{tabular}{|l|l|}
\hline Domiciliar & Originado das residências (restos de alimentos, jornais, revistas, embalagens, fraldas descartáveis); \\
\hline Comercial & $\begin{array}{l}\text { Quando produzido em estabelecimentos comerciais e de serviços (papéis, plásticos, embalagens } \\
\text { diversas); }\end{array}$ \\
\hline Público & Provenientes dos serviços públicos (limpeza urbana, limpeza de áreas de feiras livres); \\
\hline Hospitalar & $\begin{array}{l}\text { Descartado de hospitais (resíduos sépticos, como seringas, algodões, tecidos removidos, cadáveres } \\
\text { de animais usados em testes, sangue, luvas, remédios com prazo de validade vencido, resíduos } \\
\text { assépticos, que não entram em contato direto com pacientes, ou resíduos sépticos); }\end{array}$ \\
\hline Industrial & Produzidos em instalações industriais (cinzas, lobo, escórias, papéis, metais, vidros, cerâmicas); \\
\hline Agrícola & $\begin{array}{l}\text { Proveniente de atividades agrícolas (embalagens de adubos, defensivos agrícolas, ração, restos de } \\
\text { colheitas); }\end{array}$ \\
\hline Entulho & Tratando de resíduos originários da construção civil (pedras, tábuas, ladrilhos, caixotes). \\
\hline
\end{tabular}
Fonte: MANO, PACHECO, BONELLI, 2010. adaptado por NUNES, 2015.

Os Resíduos Sólidos Urbanos são componentes significativos dessa movimentação, na medida em que cada um de nós produz por dia aproximadamente $1 \mathrm{~kg}$ de resíduos, ou seja, uma fração que não é desprezível na movimentação total de materiais (SANTOS e DIAS, 2012). Para haver desenvolvimento sustentável ao meio ambiente é necessária a diminuição na geração de Resíduos Sólidos Urbanos.

Agenda 21 (1992), produto do RIO'92, composta por 40 capítulos onde trata de diversos aspectos socioeconômicos e ambientais centrados no desenvolvimento sustentável, integrado nas políticas públicas e nas práticas sociais de todos os países do mundo, é discutida a questão dos resíduos sólidos. No documento diz que o manejo ambientalmente saudável dos resíduos sólidos deve ir além do simples depósito ou aproveitamento por métodos seguros

Planeta Amazônia: Revista Internacional de Direito Ambiental e Políticas Públicas 
dos resíduos gerados, e resolver a causa fundamental do problema procurando mudar os padrões não sustentáveis de consumo. Isso implica na utilização do conceito de manejo integrado do ciclo vital, o qual apresenta oportunidade única de conciliar o desenvolvimento com a proteção ambiental.

Segundo Boff (1999), a melhor maneira de se reduzir estes resíduos sólidos consiste na tomada de consciência individual sobre a necessidade de mudanças, ocasionadas ao meio ambiente; utilizar os processos de reutilização de alguns materiais e reciclar, assim diminuirá o grande índice de resíduos sólidos. Para o autor,

Na prática, a sociedade deve mostrar-se capaz de assumir novos hábitos e de projetar um tipo de desenvolvimento que cultive o cuidado com os equilíbrios ecológicos e funcione dentro dos limites impostos pela natureza. Não significa voltar ao passado, mas oferecer um novo enfoque para o futuro comum. Não se trata, simplesmente, de não consumir, mas de consumir responsavelmente (BOFF, 1999, p.137).

Desta forma, se produzirmos menos resíduos sólidos será menos agravante ao meio ambiente. É imperioso um processo seletivo para os tipos diferenciados de resíduos, onde não causaria mau cheiro aos moradores vizinhos e nem futuras doenças. Os resíduos são diferentes em qualidade e quantidade, em volume e em composição, do que se produzia há algum tempo. Hoje, cada vez mais, é composto por materiais de difícil degradação, contribuindo para 0 aumento significativo da poluição ambiental.

Nas palavras de Figueiredo (1995, p.36):

[...] a questão dos resíduos carece de uma análise detalhada de suas implicações com relação à sustentabilidade do Planeta. Os problemas associados aos resíduos decorrem de duas componentes principais: acrescente geração de resíduos e a evolução qualitativa dos mesmos. Quanto a primeira componente, o rápido crescimento ocorre em função tanto do crescimento populacional e seu adensamento espacial, quanto do aumento da geração per capita de resíduos, impostos pelos padrões de propaganda, que intensificam a associação do consumo à qualidade de vida.

Ainda segundo Figueiredo (1995), com a evolução da sociedade aumenta o impacto ambiental, devido ao aumento da quantidade e o volume considerado a ser despejado no meio ambiente, e pelo fato destes resíduos serem mais difíceis de decompor ao solo.

\section{METODOLOGIA}

A pesquisa de caráter exploratório, foi realizada no município de Caroebe-RR, no local da disposição final dos Resíduos Sólidos, na área urbana denominada lixeira municipal, próximo a estrada de acesso a vicinal 36 (trinta e seis). 0 local de deposição dos resíduos sólidos do município começou a receber o material no ano 2000, anteriormente à área era coberta pela floresta.

A primeira etapa constituiu-se de um levantamento dos dados, com entrevistas e visitas técnicas aos gestores e pessoas envolvidas no processo referente a informações junto a

Planeta Amazônia: Revista Internacional de Direito Ambiental e Políticas Públicas 
secretária de meio ambiente do município, sobre as formas de gerenciamento dos Resíduos Urbanos no município de Caroebe /RR, em seguida, pesquisa de campo no local estudado: 0 depósito municipal. Como mostra a figura A e B abaixo.

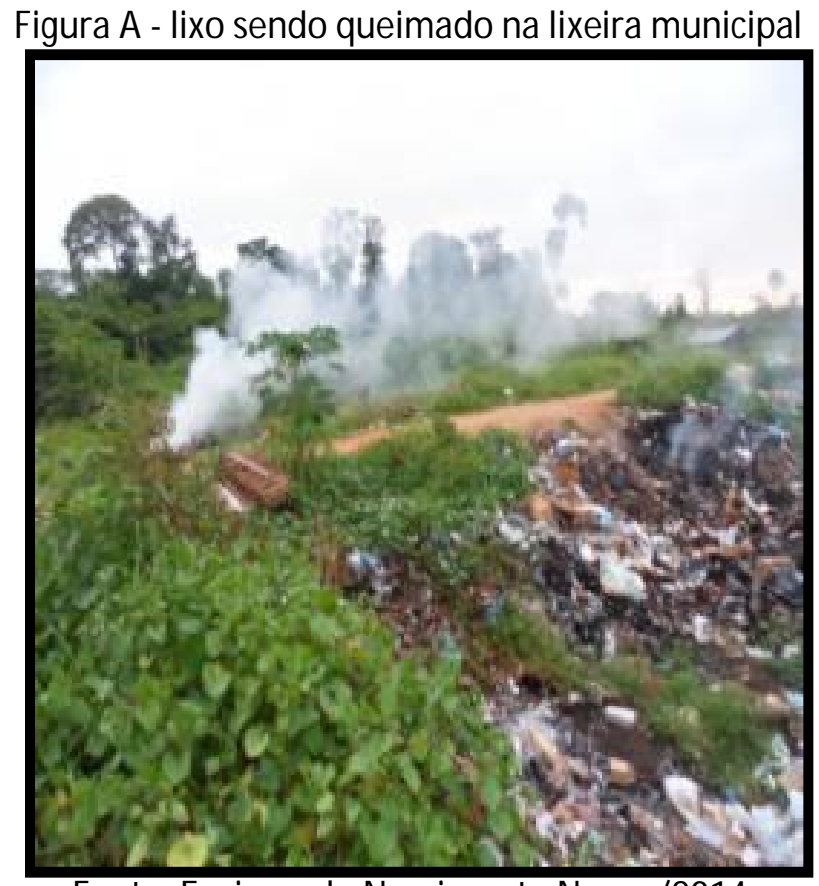

Fonte: Euzimar do Nascimento Nunes/2014.

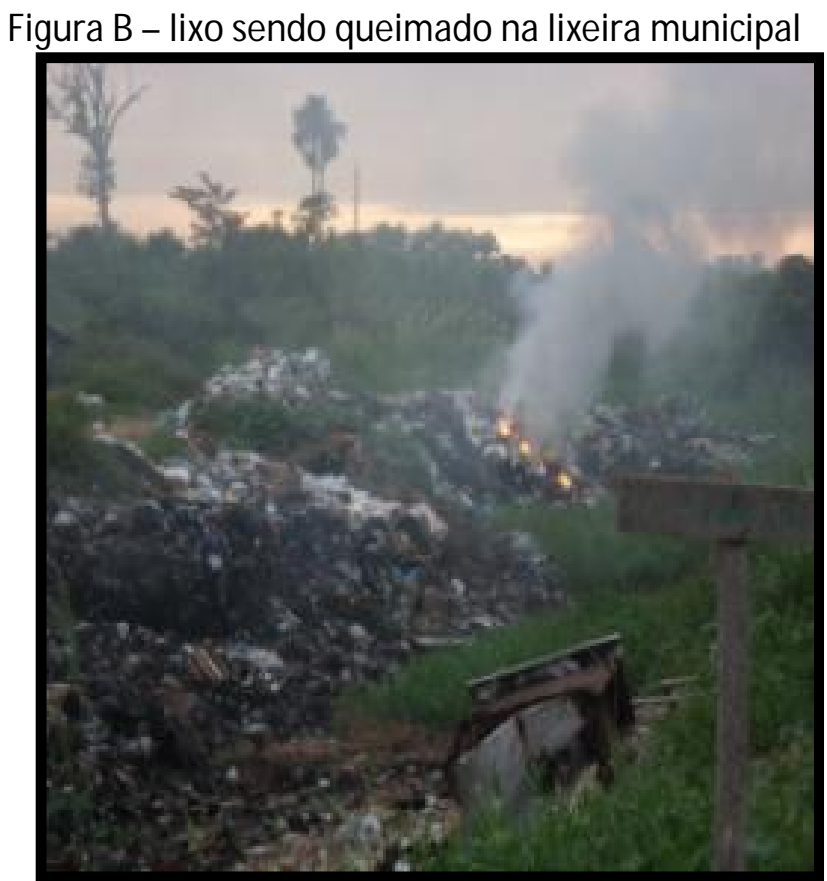

Fonte: Euzimar do Nascimento Nunes/2014.

Além dos complicadores mencionados anteriormente, deve-se destacar a poluição do ar decorrente da queima do material depositado. A fumaça, mostradas nas figuras A e B, é fator de agravamento das doenças respiratórias, principalmente em crianças e idosos.

Gil (2002, p. 17), afirma que: "A pesquisa é desenvolvida mediante os concursos dos conhecimentos disponíveis e a utilização cuidadosa de métodos, técnicas e outros procedimentos científicos".

\section{RESULTADOS E DISCUSSÕES}

Analisando os dados coletados diante das informações e pesquisas realizadas, 0 índice de geração de resíduos pela sociedade, segundo informações, é considerado razoável pelo total de habitantes. 0 município possui um local dentro da área urbana para disposição dos RSU criado pela prefeitura, porém, não é adequado, pois existem moradias ao seu entorno, além de não seguir as normas preconizadas para o destino final desses resíduos.

A prefeitura municipal, por meio da Secretaria Municipal de Infraestrutura, destacou as seguintes informações: a coleta dos resíduos é realizada duas vezes por semana, sendo que, por dia, faz cinco viagens para recolher os resíduos totais do município. Em cada viagem o caminhão leva em torno de 1000 quilos de resíduos, totalizando 5000 mil quilos por dia, e, por semana, 10.000 quilos ao todo. 0 número de trabalhadores, nesta coleta, é de quatro pessoas que utilizam um caminhão. 0 caminhão de lixo que é utilizado para o recolhimento 
dos Resíduos é adequado, conforme a figura 4.

Quanto à disposição dos resíduos, é de forma inadequado, devido a não possuir um aterro sanitário, contaminando os recursos hídricos superficiais e os subterrâneos. E também disseminados com a propagação de doenças com efeitos graves à saúde pública expondo a riscos a população e, consequentemente, contribuindo para a proliferação de doenças ocasionadas pelo que é gerado dos RSU. Deve-se destacar, ainda, a presença de moradias ao seu entorno, como: a poluição visual, a poluição dos solos e cursos de água, em decorrência do mau acondicionamento.

Figura 4 - Caminhão para Recolher Lixo

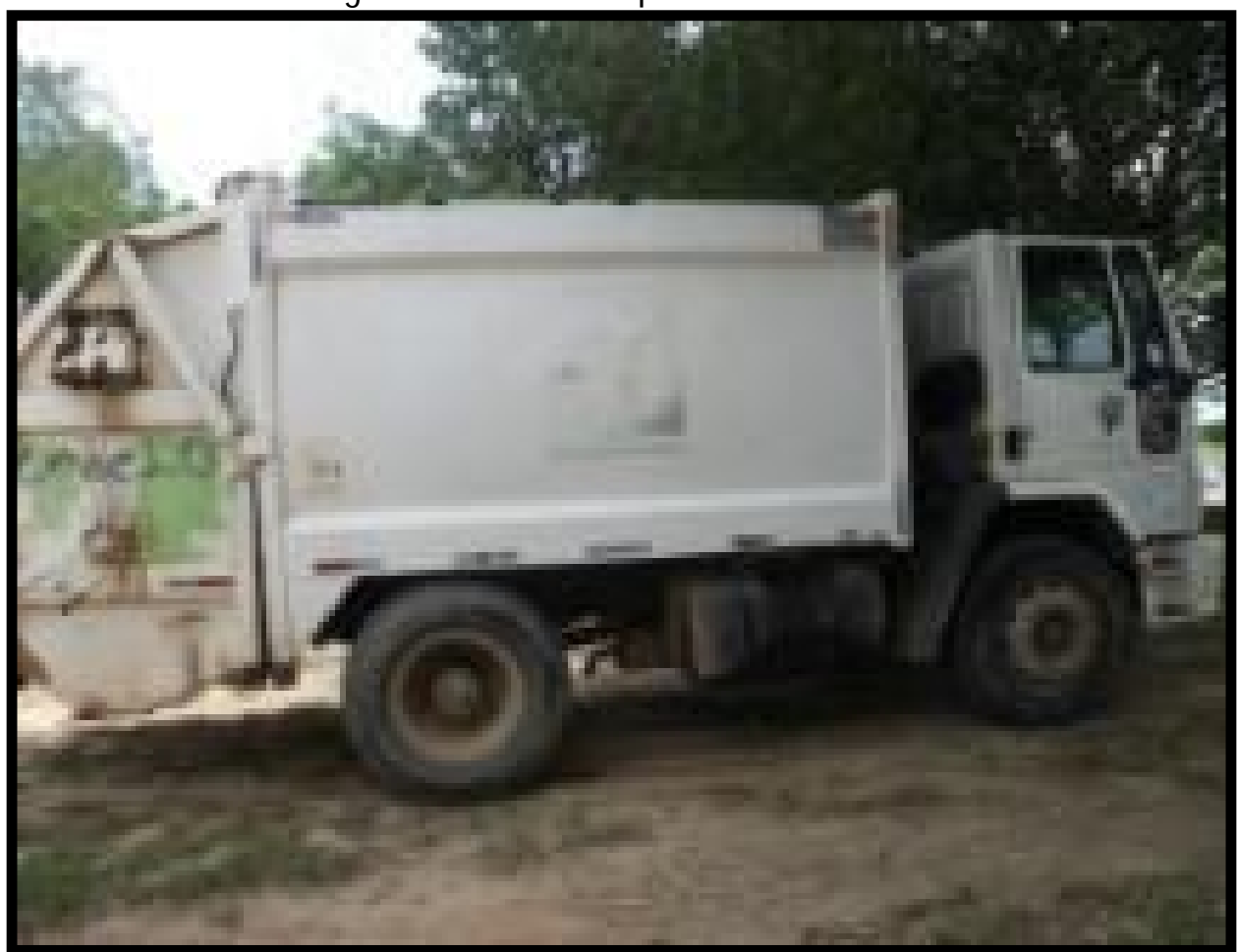

Fonte: Euzimar do Nascimento Nunes/2014.

No município de Caroebe, há um comprador de materiais recicláveis que envia para Manaus - AM, para um destino final, com exceção dos litros de vidro que vão para o Rio Grande do Norte. Os resíduos comercializados são alumínio (panelas, latas de refrigerantes, bloco de peça de moto), plástico, de modo geral, garrafas e ferro.

Ainda, segundo entrevista com o responsável, informa que há apenas um comprador em cada município para esta fábrica. Ela já trabalha a 15 anos, tendo um comprador em Caroebe, um em São João da Baliza e outro em Entre Rios, todos fornecendo para Manaus. As latinhas de refrigerante são enviadas quinzenalmente e mensalmente Junto com ferro, e é enviado para Manaus - AM. Quando se acumula em torno de 15 (quinze) mil quilos, enquanto os litros são enviados quando se acumulam 20 (vinte) mil litros por mês, considerando as das vicinais e zona urbana, segundo informações fornecidas pelo comprador. Pode-se ver meIhor conforme o quadro 2 a seguir. 
Quadro 2 - M ateriais Recicláveis no Município de Caroebe.

\begin{tabular}{|l|r|}
\hline \multicolumn{2}{|c|}{ TIPOS DE MATERIAIS RECICLÁVEIS NO MUNÍCIPIO DE CAROEBE } \\
\hline TIPO DE MATERIAL & VALOR EM R $\mathbf{~} \mathbf{~ K g}$ \\
\hline Latas de refrigerantes e cervejas & 1,00 real \\
\hline Bloco de alumínio & 0,75 centavos \\
\hline Quadro de bicicleta & 0,25 centavos \\
\hline Plásticos, garrafas pet & 0,25 centavos \\
\hline Litros de modo geral & 0,10 centavos \\
\hline
\end{tabular}

Fonte: Pesquisa in loco. Organizada por: Euzimar do Nascimento Nunes/2014.

Todos esses materiais são depositados em um quintal. Logo em seguida há uma classificação por tipo de materiais, até adquirir a medida de kilos adequada para serem enviados a fabrica, para seu destino final.

\section{CONSIDERAÇÕES FINAIS}

O município de Caroebe não dispõe de um local adequado para a disposição final dos RSU gerados, tão pouco há a implantação de coletas seletivas, ou seja, todos os resíduos são depositados no mesmo local. A disposição final é feita a céu aberto, colocando em risco a população sobre a fragilidade de determinadas doenças a serem adquiridas, desta forma, aumenta os impactos ambientais e a poluição atmosférica.

0 aumento populacional contribuiu para um aumento na geração de Resíduos Sólidos Urbanos, naturalmente, é preciso criar métodos para gerenciar os resíduos produzidos, diminuindo a geração, bem como por meio das atividades de educação ambiental buscando a sensibilização da comunidade sobre os riscos e consequências futuras. Criar projetos e campanhas de incentivo para a comunidade, mostrando formas de diminuir a geração de resíduos, e como reaproveitar; colocando sobre uma breve explanação o processo de coleta seletiva e a criação de um aterro adequado para disposição final dos resíduos.

Esta pesquisa foi de suma importância para o município, pois foi advertido sobre o índice de RSU gerado pela população e seus meios de reaproveitamento. Para a geografia podemos perceber os impactos sofridos ao meio ambiente ocasionado devido a geração de resíduos, e os corpos hídricos que já foram ou podem vir a ser afetados em decorrência de não se ter um local adequado para disposição final. Para os professores foi bom, para que trabaIhem com seus educandos métodos de colaboração para a diminuição de Resíduos Sólidos Urbanos, e explicar as complicações futuras à saúde deles mesmos. Vale frisar que somos todos responsáveis no processo de construção de uma sociedade melhor para todos.

\section{REFERÊNCIAS}

BOFF L. Saber cuidar. Ética do humano: compaixão pela terra. Petrópolis: Vozes; 1999. CARVALHO, Anésio Rodrigues; OLIVEIRA, Maria Vendramini Castrignado. Princípios Básicos do Saneamento do Meio. 10ำ edição. São Paulo-SP. Editora SENAC. 2010. 
CHRISTOFOLETTI, A. Impactos no meio ambiente ocasionado pela urbanização do mundo tropical. In: SOUZA, M. A. de. ; SANTOS, M; SCARLATO, F. C; ARROYO, M . 0 novo mapa do mundo Natureza e Sociedade de hoje: uma leitura geográfica. 3. Ed.

FIGUEIREDO, Paulo Jorge M oraes. A sociedade do lixo: os resíduos, a questão energética e a crise ambiental. 2a ed. Piracicaba: UNIM EP, 1995.

GIL, Antônio Carlos. Como Elaborar Projetos de Pesquisas, São Paulo, 4ํe ed. Editora Atlas S.A. 2002.

GOMES, L. P. et al. Alternativa de disposição final de resíduos sólidos urbanos: trincheiras em série. Brasília, 2003.

INSTITUTO BRASILEIRO DE GEOGRAFIA E ESTATÍSTICA - IBGE. Cidades - Roraima Caroebe. Disponível em: \ttp://www.ibge.gov.br/cidades>. Acessado em: 11 dez. 2014.

INSTITUTO BRASILEIRO DE GEOGRAFIA E ESTATÍSTICA - IBGE. Pesquisa Nacional por amostra de domicílios PNAD, 2014. Disponível em: 〈http://ibge.gov.br.acessado>. Acessado: $11 \mathrm{dez}$. de 2016.

LEI № 12.305, de 2 de agosto de 2010. Institui a Política Nacional de Resíduos Sólidos; altera a Lei no 9.605, de 12 de fevereiro de 1998; e dá outras providências. Disponível em: http://www.planalto.gov.br/ccivil_03/_ato2007-2010/2010/lei/l12305.htm. Acessado em: 13 dez. 15

M ANO, Eloisa Biasotto; PACHECCO, Élen B. A.V; BONELLI, Cláudia M. C. Meio Ambiente Poluição e Reciclagem. São Paulo-SP, 2ํe edição. 2010.

MINISTÉRIO DO MEIO AMBIENTE - MMA. AGENDA 21. Disponível em: ঝttp://www.mma. gov.br >. Acessado em: 11 dez. 2014.

PLANO DE DESENVOLVIMENTO LOCAL INTEGRADO E SUSTENTÁVEL. Agenda Executiva 2001/2004. Pág. 29,30.

MINISTÉRIO DO MEIO AMBIENTE - MMA. Planos de Gestão de Resíduos Sólidos: Manual de Orientação. Apoiando a implantação da Política Nacional de Resíduos Sólidos: Do nacional ao Local. M inistério do M eio Ambiente. 2012. Brasília- DF.

PROSAB. Resíduos Sólidos e Urbanos: Aterro Sustentável para M unicípio de Pequeno Porte. Florianópolis-SC. 2003.

SANTOS, Maria Cecília Loschiavo; DIAS Sylmara Lopes Francelino Gonçalves. Resíduos Sólidos Urbanos e Seus Impactos Socioambientais. São Paulo: IEE-USP, 2012.

SECRETARIA DE PLANEJAM ENTO E DESENVOLVIM ENTO DE RORAIMA -SEPLAN/RR. Perfil Socioeconômico do Estado. Boa Vista, ed. 2009.

WIKITRAVEL. Localização do município de Caroebe. MAPA DA BR-210. Disponível em: ४ttp:// www.wikitravel.org/pt/Roraima>. Acessado em: 12 dez. 2014.

ZVEIBIL, Victor Zular. BRASIL. M inistério da Ação Social. Secretaria Nacional de Saneamento, Centro de Estudos e Pesquisas Urbanas. Cartilha de Limpeza Pública. Brasília, 1991.

Artigo recebido em 26 de agosto de 2016.

Aprovado em 31 de dezembro de 2016. 